\title{
A COSMOLOGIA DE FORA E A HISTÓRIA POR DENTRO
}

MARIA CRISTINA DOS SANTOS ${ }^{1}$

PUCRS

\section{RESENHA}

FELIPPE, Guilherme Galhegos. A cosmologia construída de fora: a relação com o outro como forma de produção social entre os grupos chaquenhos no século XVIII. Jundiaí: Paco Editorial, 2014. 376p.

A tese de Guilherme Galhegos Felippe, defendida no Programa de Pós-Graduação em História da Universidade do Vale do Rio dos Sinos em 2013, sob orientação da professora Eliane Cristina Deckmann Fleck, recebeu o Prêmio CAPES na área de História de 2014, com justiça e necessidade. Agora sua merecida publicação em livro propõe um grande desafio às comunidades acadêmicas da História e da Antropologia sobre os modos de fazer pesquisa e a produção do conhecimento sobre os indígenas no passado. E isso merece algumas considerações.

Primeiro porque Guilherme G. Felippe se arrisca a estudar os grupos da região do Chaco, região a que os próprios colonizadores e missionários tardaram um século e meio em se aproximar, a não ser por esporádicos contatos. A razão dessa demora encontrava-se na grande diversidade cultural, linguística e política dos grupos que ali se encontravam. A tabela apresentada ao final da Introdução (p.34-35) dá uma ideia acerca dessa diversidade da região, onde se encontram

\footnotetext{
${ }^{1}$ Doutorado em História da América e Pós Doutorado em Antropologia da América na Universidad Complutense de Madrid. É professora adjunta do PPGH-PUCRS, e Editora da Revista Estudos IberoAmericanos. Tem experiência na área de História da América Colonial, atuando principalmente nos seguintes temas: metodologia da pesquisa, teorias da história, etnohistória, história indígena e política indigenista. E-mail: $\underline{\text { mcstita@pucrs.br . }}$
} 
Tobas, Zamucos, Mataguayos, Abipone, Mbayá, Guaná, Mocovi, entre outros. Os modelos de conquista e evangelização utilizados nas demais regiões da América com outros grupos indígenas não podiam ser simplesmente transpostos para os grupos chaquenhos. A aproximação colonial com os chaquenhos e a pesquisa de Felippe avançam por um período histórico conturbado para a coroa espanhola: Guerra de Sucessão, ascensão da dinastia dos Bourbons ao trono espanhol, implantação de um projeto de reforma administrativa amparado nos pressupostos racionais do despotismo esclarecido e uma sede de recolonizar, reassumir a posse dos territórios para usufruir ao máximo das vantagens exploratórias das potencialidades de suas colônias. Essa antessala da conjuntura política, econômica e cultural indica uma pequena parte dos desafios na realização da pesquisa e reflexão empreendidas por Felippe.

Segundo porque, como bem explicita o autor, sua intenção é "analisar esse contato histórico, privilegiando, ao máximo, a análise do comportamento indígena" (FELIPPE, 2014, p. 18). Tal intenção carrega consigo um compromisso teórico e um desafio metodológico há muito presente na agenda acadêmica, mas poucas vezes cumprido, menos ainda com êxito. Decorrência, em parte, de um modismo teórico vigente nas décadas de 1980 e 90 e, por outra parte, consequência de uma posição confortável assumida por muitos pesquisadores que privilegiam o contato interétnico em si como objeto de pesquisa ${ }^{2}$. Se o período analisado é o do contato, nada mais seguro do que enfatizar as alterações advindas desse contato, com o qual as sociedades indígenas ficam relegadas a um comportamento reativo, que sempre será coadjuvante de outra sociedade envolvente que é detentora do poder do registro. Dentro dessa lógica de análise, elementos como a cosmologia dos nativos não entrariam em questão. Portanto, a proposta que Felippe apresenta e desenvolve, evidencia como fazer o que Sahlins chamou de uma história de qualidade: "não se pode fazer uma história de qualidade, nem mesmo história contemporânea sem respeito às ideias, ações e ontologias que não são e nunca foram as nossas próprias" (SAHLINS, 2001, p. 29).

\footnotetext{
${ }^{2}$ Bastante esclarecedor sobre esse tema é a coletânea de textos organizada por Sérgio Micelli (1999), em particular o texto Etnologia Brasileira, de Viveiros de Castro.
} 
Terceiro, e não menos importante, é que Guilherme Felippe conseguiu fazer tudo a que se propôs: a análise de uma conjuntura colonial conflitante e uma acurada reflexão antropológica sobre a cosmologia e a ontologia dos grupos chaquenhos, fundamentadas numa extensa e intensa pesquisa documental, bem como no diálogo atual e profícuo com a literatura antropológica. Cabe, portanto, pontuar alguns momentos fundamentais dessa empreitada.

No primeiro capítulo, Os mitos indígenas como construção da realidade, Felippe começa por articular a diferença entre o conhecimento objetivo do pensamento moderno com o conhecimento subjetivo, definido por Lévi-Strauss como fonte de saber dos grupos indígenas. A surpresa do demarcador espanhol Félix de Azara (1809) ao ver que os nativos conseguiam ter o manejo agrícola de plantas não nativas, como algodão, amendoim e vagens, ou até mesmo o sal, produzido a partir da queima de ervas específicas, serve como ponta de lança para a discussão clássica à antropologia que se refere às relações entre Natureza e Cultura. A partir daí a mitologia indígena dos diversos grupos aparece como fonte do conhecimento ameríndio a partir da fundamentação teórica do perspectivismo e do multinaturalismo, e numa leitura minuciosa e atenta das fontes coloniais. No conjunto, os mitos narram a constituição do mundo, onde aparecem situações de zoomofismo, de controle dos astros e apreensão de fenômenos celestes, as restrições alimentares como ordenadoras de comportamentos e, por fim, a apropriação mitológica de elementos externos, tais como o diabo, o inferno e o pecado:

não são os elementos externos que atualizam o mito, e sim este último que se apropria dos primeiros, integrando-os em sua estrutura. E nessa condição que o diabo das narrativas mitológicas supracitadas figura como um dos agentes difusores de atividades a serem combatidas pelos índios, sem que isso representarem os mesmos valores simbólicos/funcionais com os quais atuavam no ocidente cristão (FELIPPE, 2014, p. 71).

De forma complementar, aparecem as oposições duais estruturantes da vida indígena, como terra e céu, homem e mulher, índio e branco. Ao final desse primeiro capítulo, aparece parte da justificativa do título, onde, 
para além das diferenças entre uma versão e outra, o mito sobre o surgimento das mulheres narra a aparição de um elemento de fora que é interiorizado pelos membros que já compartilham um socius. É esse movimento de internalização que ocorre por uma via de acesso entre o céu e a terra, as mulheres representam o Outro, aquilo que não pertence ao grupo no qual são inseridas, fazendo surgir a distinção entre o estrangeiro e o conterrâneo, o distante e o próximo, o externo e o interno (FELIPPE, 2014, p. 91).

A partir do segundo capítulo, começam a aparecer, na prática, as relações que os grupos chaquenhos mantinham com o outro, por meio da análise de mais um tema fundamental na antropologia: a guerra. Lévi-Strauss, em a Guerra e o comércio da América do Sul, estabeleceu que os conflitos guerreiros e as trocas comerciais constituem dois aspectos opostos e indissolúveis de um único e mesmo processo social ([1942]1976, p. 338). Numa crítica a Lévi-Strauss, Pierre Clastres afirma que a guerra em si mesma funciona como um dispositivo sociológico para manutenção da autonomia e unidade dos grupos nativos: "a sociedade primitiva é contra o Estado, na medida em que é uma sociedade para-a-guerra, mas ela também é, ao mesmo tempo, uma sociedade contra o guerreiro" (CLASTRES, 1982, p. 240 e 1977, p. 203). Estudos etnológicos mais recentes evidenciam que os grupos das terras baixas, nos quais se incluem os chaquenhos, possuem um passado mais complexo que a minimalista, segmentária e sectária sociedade primitiva clastreana. A guerra, como comunicação e abertura ao outro, terá espaço destacado na dissertação de Viveiros de Castro, Os deuses canibais, publicada em 1986. Nessa pesquisa, fruto de uma pesquisa etnográfica com os Araweté da Amazônia, a guerra aparece como comunicação entre o mundo natural e sobrenatural. Esse nível de análise e reflexão antropológica parecia não ter espaço numa pesquisa com base na documentação histórica. Esse mesmo autor demonstrará, alguns anos depois, que tal análise era possível, ao publicar o Mármore e a Murta ([1992] 2002), evidenciando a inconstância da alma tupiguarani, por meio da análise de sermão do Padre Antônio Vieira de 1657. 
No capítulo intitulado $A$ guerra como motor social, Felippe discute o conceito de "violência" a partir de Carlos Fausto (2001) e apresentanos uma sequência de registros documentais onde as guerras/assaltos/furtos realizados pelos grupos chaquenhos contra os núcleos coloniais podem, sim, ser vistos como uma parte importante da vida indígena, onde mais que a vitória, importava mesmo era a guerra em si. Segundo o autor, "a guerra era um dos meios mais eficientes de se formar a pessoa indígena e de se criar vida social entre os índios por isso era fundamental sua continuidade- (...) e sua não extinção" (FELIPPE, 2014, p. 122).

Os dois últimos capítulos são dedicados ao comércio e principalmente à economia indígena. Estes se desenvolvem num contexto econômico e comercial da região chaquenha, intermediária entre um polo de comércio e contrabando, como o porto de Buenos Aires, e o outro polo das zonas urbanas, dedicadas à mineração em torno de Potosí, ainda que esta última já estivesse em decadência no século XVIII.

O capítulo três inicia com a discussão sobre a maneira como os chaquenhos administravam seus bens a partir da análise da distribuição, circulação e consumo de itens entre os índios. Os registros coloniais constantemente enfatizam a incapacidade dos indígenas em atribuir corretamente os valores financeiros envolvidos nessas trocas. O que evidencia, segundo Felippe, que para os índios "importava menos o que era trocado do que a troca em s" (2014, p. 210). Entretanto, o foco desse capítulo centra-se nas formas adotadas pelos nativos para integrarem-se ao sistema comercial da colônia, potencializando suas trocas tradicionais e a reciprocidade como forma de selar alianças.

Num desdobramento da economia indígena, o último capítulo analisa a produção e o consumo alimentar como uma forma de manutenção das relações mantidas pelos chaquenhos tanto na esfera cosmológica como da Natureza. O regime de prodigalidade, registrado quase sempre como condenação na documentação colonial, evidencia que os índios estavam atuando conforme a relação que mantinham com o meio natural em que estavam colocados. A escassez de comida era tão esperada quanto a abundância, e tudo dependia da capacidade dos nativos de se relacionarem entre si o com seu ambiente. 
Se os índios eram imprevidentes, de acordo com a visão do colonizador, é porque suas metas eram baseadas em parâmetros distintos: a quantidade de alimento que pretendiam produzir era menor que a almejada pelos espanhóis na mesma razão em que a quantidade de tempo livre que esperavam ter para o ócio era muito maior que a oferecida por eles (FELIPPE, 2014, p. 312).

Mas é nesse último capítulo que aparece com todo vigor a aposta teórica de Felippe pelo multicuturalismo. Evidencia-se, assim, uma construção intelectual coerente e lógica, que não é avessa ao tema do contato, mas faz dele uma alavanca para sua análise cultural. Isso aparece de forma mais evidente quando Felippe considera
oportuno retomar as discussões feitas no primeiro capítulo acerca da oposição cosmológica prefigurada pelos modernos entre cultura e natureza e do multiculturalismo que prevê a existência de um mundo pronto como palco de atuação de uma pluralidade cultural (FELIPPE, 2014, p. 306).

A análise e interpretação de Felippe sobre temas como a guerra, a reciprocidade, o regime de produção e consumo alimentar, assim como das recusas e escolhas em relação à domesticação de animais, por meio do enfoque perspectivista, possibilitou ao autor centrar seu foco nas características identitárias dos indígenas, sem estancar sua análise nas relações que se estabeleceram por causa do contato com os ocidentais. Nesse último capítulo, é possível perceber com clareza como o sistema mitológico dos chaquenhos atua como uma força centrípeta, onde a sociabilidade funciona como um eixo atrativo de elementos exógenos para a manutenção da cultura. As práticas ritualísticas, ligadas à construção da pessoa, atuaram como catalisadores das relações sociais e foram responsáveis pela inserção e adaptação de elementos movidos tanto pela reciprocidade como por elementos trazidos de fora.

Quando os grupos indígenas do Chaco recusaram a internalização dos métodos produtivos e do regime de consumo do sistema econômico moderno, não estavam, de forma alguma, criando mecanismos de refração generalizada à penetração de conhecimentos exógenos (...). Era, justamente, para não deixarem de 
estar abertos à incorporação de elementos de fora que os chaquenhos rechaçaram a agricultura moderna e a sua forma de administrar os bens, evitando, assim, a proliferação de práticas individualistas focadas no enriquecimento privado. (...) aproveitando-se das rotas mercantis para fazer circular os bens, não substituíram o valor simbólico da troca pelo valor financeiro dos produtos. Assim, reciprocidade, enquanto mobilizadoras social, não perdeu sua função para o individualismo monetário das relações mercantis. Da mesma forma, o modo de produção alimentar moderno implicava na reestruturação de elementos cosmológicos ligados à compreensão que os índios possuíam da realidade que os cercava (FELIPPE, 2014, p. 325).

A cosmologia construída de fora mostra o grande desafio de ver as potencialidades da História por dentro. Não basta somente recompilar dados empíricos e apresentar conceitos oriundos de uma discussão teórica atual se esses dois elementos não conversarem de forma convincente, autêntica e, sobretudo, explicativa. Houve um tempo em que a produção acadêmica diferenciava os estudos históricos que se valiam de conceitos da antropologia. Houve um tempo, na academia brasileira, em que os historiadores que se propunham a explicar lógicas culturais internas de grupos indígenas no passado eram quase considerados marginais por serem excessivamente relativistas. Houve um tempo em que não fazia parte da agenda do historiador estudar as lógicas de grupos indígenas sem necessariamente passar pelo contato interétnico em confronto com um Estado. Houve um tempo na História em que uma perspectiva de longa duração jamais poderia se articular com dados tão efêmeros e contaminados como os registros de um grupo sobre outro. Houve um tempo em que a proposta de uma nova história indígena atualizou alguns conceitos, mas não sua abordagem sobre o tema. Tomara que o estudo apresentado por Guilherme Galhegos Felippe tenha transformado esse tempo em passado e inaugure uma época com mais autonomia e rigor à pesquisa histórica sobre grupos indígenas.

\section{Referências bibliográficas}


AZARA, Felix de. Viajes por la América Meridional. Buenos Aires: El Elefante Blanco. 1998 [1809]. Tomo II

CLASTRES, Pierre. A sociedade contra o Estado: investigações de antropologia política. Porto: Afrontamento, 1977.

Arqueologia da Violência. São Paulo: Brasiliense, 1982.

FAUSTO, Carlos. Inimigos Fiéis: guerra e xamanismo na Amazônia. São Paulo: Edusp, 2001.

FELIPPE, Guilherme Galhegos. A cosmologia construída de fora: a relação com o outro como forma de produção social entre os grupos chaquenhos no século XVIII. Jundiaí: Paco Editorial, 2014.

LÉVI-STRAUSS, Claude. Guerra e comércio entre os índios da América do Sul. In: SCHADEN, Egon (Org.). Leituras de Etnologia brasileira. São Paulo: Companhia Editora Nacional, 1976 [1942]. p. 325-339.

MICELLI, Sérgio. O que ler na ciência social brasileira (1970-1995): I Antropologia. São Paulo: Sumaré, 1999.

SAHLINS, Marshall. Como pensam os “Nativos”. São Paulo: Edusp, 2001.

VIVEIROS DE CASTRO, Eduardo. Araweté: Os Deuses Canibais. Rio de Janeiro: Zahar, 1986.

O mármore e a murta: sobre a incostância da alma selvagem. Revista de Antropologia, São Paulo, v. 35, p. 21-74, 1992.

"Etnologia brasileira". In: MICELLI, Sérgio (Org.). O que ler na ciência social brasileira (1970-1995): I Antropologia. São Paulo: Sumaré, 1999, p. 50-62. 